\title{
A Glassification of the Klebsiella Group
}

\author{
By S. T. COWAN, K. J. STEEL, CONSTANCE SHAW* \\ National Collection of Type Cultures, London, N.W. 9 \\ AND J. P. DUGUID \\ Bacteriology Department, University of Edinburgh
}

(Received 4 July 1960)

\begin{abstract}
SUMMARY
Klebsiella strains are divided into six categories on the following reactions: fimbriation, production of gas from glucose at $37^{\circ}$, acid from lactose and dulcitol, methyl red test, acetoin production, citrate, urease, gluconate, malonate, lysine decarboxylase, growth in the presence of $\mathrm{KCN}$ and ability to produce gas from lactose at $44^{\circ}$. Five of the six categories are assigned specific rank, the sixth subspecific rank. The tests enable Friedländer's pneumobacillus to be distinguished from Aerobacter aerogenes. A new species, Klebsiella edwardsii, and a new subspecies, $K$. edwardsii var. atlantae, are named. Neotype strains of old species are proposed, holotypes of the new species and variety designated, and the catalogue numbers in the National Collection of Type Cultures and American Type Culture Collection given.
\end{abstract}

\section{INTRODUCTION}

Although the Klebsiella group is easily subdivided into serotypes by differences in the capsular antigens, a subdivision by biochemical tests into species is more difficult. The group comprises organisms that are non-motile, capsulate Gramnegative rods, and they have been named Klebsiella pneumoniae, $K$. friedlaenderi, $\boldsymbol{K}$. rhinoscleromatis, $\boldsymbol{K}$. ozaenae and Bacterium lactis aerogenes (synonym Aerobacter aerogenes Beijerinck). Two species, $K$. rhinoscleromatis and $K$. ozaenae, have characters that are reasonably distinctive, and the real problem is to decide whether it is possible to distinguish between $B$. lactis aerogenes and $K$. pneumoniae $(K$. friedlaenderi). This problem arises from the inadequacy of the early descriptions of these species for, as Edwards (1929) pointed out, Friedländer did not indicate whether his pneumobacillus fermented lactose or acted on milk.

Frankland, Stanley \& Frew (1891) found that their strain (which they called Friedländer's pneumococcus) fermented glucose, sucrose, lactose, maltose, raffinose, dextrin and mannitol producing ethanol and acetic acid, but it did not ferment glycerol or dulcitol. Grimbert's (1895) strains fermented glycerol and dulcitol and produced lactic acid, and combining the findings of these workers Grimbert \& Legros (1900) recognized two races distinguished by end-products of fermentation. However, they thought that separation into two species, Bacterium lactis aerogenes and Friedländer's bacillus, was unjustified, a conclusion supported by Edwards (1929).

* Present address: Lister Institute of Preventive Medicine, Elstree, Hertfordshire. 


\section{S. T. Cowan, K. J. Steel, C. Shaw and J. P. Duguid}

Duguid (1959) reopened discussion of the problem when he suggested that saprophytic Klebsiella aerogenes were fimbriate while pathogenic $K$. pneumoniae, $K$.rhinoscleromatis and $K$. ozaenae were non-fimbriate. This new approach seemed so hopeful that the morphological and certain biochemical reactions of 176 strains were investigated; the results are presented in this paper.

\section{METHODS}

Strains. In all, 182 strains were studied; 176 were regarded as klebsiellas as they had the following characters. Generally capsulate, Gram-negative, non-motile rods. Colonies moist and generally mucoid, not pigmented. Gelatin not liquefied. Catalase-positive; oxidase-negative. Glucose and many other sugars fermented, usually with the production of both acid and gas. Most strains fermented adonitol and inositol, and most were known to have capsular antigens of the Klebsiella group (Report, 1958). Included were:

(a) Strains received from Dr E. P. Snijders, Amsterdam, as serotypes A-F (Goslings \& Snijders, 1936) later redesignated 1-6 by Kauffmann (1949).

(b) Type strains of serotypes 7-69 from Dr Ida Ørskov, Dr P. R. Edwards and Dr P. N. Edmunds.

(c) Many strains of serotypes 1-6, and 30 strains of respiratory origin (serologically unselected) from Dr P. R. Edwards.

(d) Strains deposited in the National Collection of Type Cultures with such names as Bacillus lactis aerogenes, Bacterium aerogenes, B. capsulatus, B. pneumoniae, $B$. ozaenae and B. rhinoscleromatis. Among this group of strains was NCTC 204 which in the 1st edition of the Catalogue (1922) was described as 'Probably original Friedländer strain'.

For comparison, 6 other strains with IMViC reactions -+++ were studied:

NCTC 9735, a motile strain with the capsular antigen of Klebsiella serotype 47.

NCTC 10,006, type strain of Enterobacter aerogenes Hormaeche \& Edwards.

NCTC 10,005, type strain of Enterobacter cloacae (Jordan) Hormaeche \& Edwards.

NCTC 9529, a motile, slow gelatin-liquefying strain from water; isolated at the Metropolitan Water Board Laboratory.

NCTC 9741, 9743, motile, rapid gelatin-liquefying strains, isolated by Dr E. Hormache from wounds.

Biochemical methods used were, in general, those recommended in Report (1958).

The exceptions were as follows:

Indole: oxalic acid paper method of Holman \& Gonzales (1923).

Methyl red (MR) and Voges-Proskauer (VP; acetoin): strains were grown in glucose phosphate peptone medium for 5 days at $30^{\circ}$. Acetoin detected by Barritt's (1936) method.

$\mathrm{H}_{2} \mathrm{~S}$ production: detected by lead acetate papers over broth containing cysteine (Clarke, 1953).

Citrate: Koser's (1923) medium was inoculated with a straight wire from a saline suspension. Positives were confirmed by subculture. 
$K C N$ : the method was that used in the Salmonella Reference Laboratory, Colindale (Dr Joan Taylor, personal communication), a modification of that described by Møller (1954).

Malonate and phenylalanine: using the combined medium of Shaw \& Clarke (1955).

Decarboxylase activity: determined by Møller's (1955) and Falkow's (1958) methods but, as these sometimes differed, only the results of Møller's method are recorded here.

Other tests, not mentioned in Report (1958) were:

Fimbriae: (Duguid, Smith, Dempster \& Edmunds, 1955; also called 'pili' by Brinton, 1959) observed by the electron microscope in gold-palladium shadowed films of washed, formaldehyde-fixed bacilli from broth cultures.

Adhesins: MS adhesin was demonstrated by haemagglutination tests with guineapig red cells with and without $0.5 \% \mathrm{D}$-mannose, and MR adhesin by similar tests with tanned ox red cells (Duguid, 1959). These examinations were made on serial aerobic cultures grown in nutrient broth for $48 \mathrm{hr}$. at $37^{\circ}$ and in a repeat series of cultures at $30^{\circ}$.

Capsules: demonstrated in wet India ink films of the bacilli grown in broth and on an excess-sugar agar medium at $37^{\circ}$ (Duguid, 1951).

Gluconate oxidation: by the method of Shaw \& Clarke (1955), using as control, medium without gluconate to show the absence of reducing sugar in the capsular material.

4.4 $4^{\circ}$ test: inoculated tubes of MacConkey broth were held in a water bath at $44( \pm 0 \cdot 1)^{\circ}$ for $48 \mathrm{hr}$. Gas in Durham's tube was recorded as positive; acid without gas was recorded as negative (Report, 1935).

Fermentation $v$. oxidation of glucose: method of Hugh \& Leifson (1953).

Serological type was that indicated by the donor, but, in addition, Dr P. R. Edwards kindly typed several previously untyped strains.

\section{RESULTS}

In addition to the group characters described under Methods the following were common to the 176 klebsiella strains: glucose was fermented (Hugh \& Leifson, 1953) and acid was produced from xylose, arabinose, rhamnose, maltose, trehalose, mannitol, sorbitol, and salicin. $\mathrm{H}_{2} \mathrm{~S}$ was produced from a cysteine-containing medium. None digested inspissated serum. Arginine and ornithine decarboxylase activity was not found. Characters common to all strains are of no value in subdividing the group, and were not considered in sorting the results of tests.

All strains except ten were found by the India ink method to be capsulate. The division between the capsulate and the non-capsulate strains was not clear-cut. Thus, certain strains produced visible capsules on only a proportion of rods; a few were capsulate only on excess-sugar medium or produced very soft, indefinite capsules, doubtfully distinguishable from loose slime.

In sorting the characters of the $\mathbf{1 7 6}$ strains three distinct patterns were at once discernible; these corresponded to Bacterium lactis aerogenes (referred to as A), Klebsiella rhinosleromatis (R), and $K$. ozaenae $(\mathrm{O})$. 


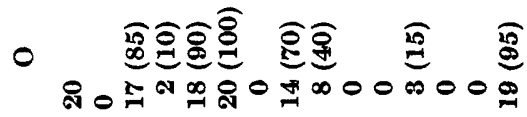
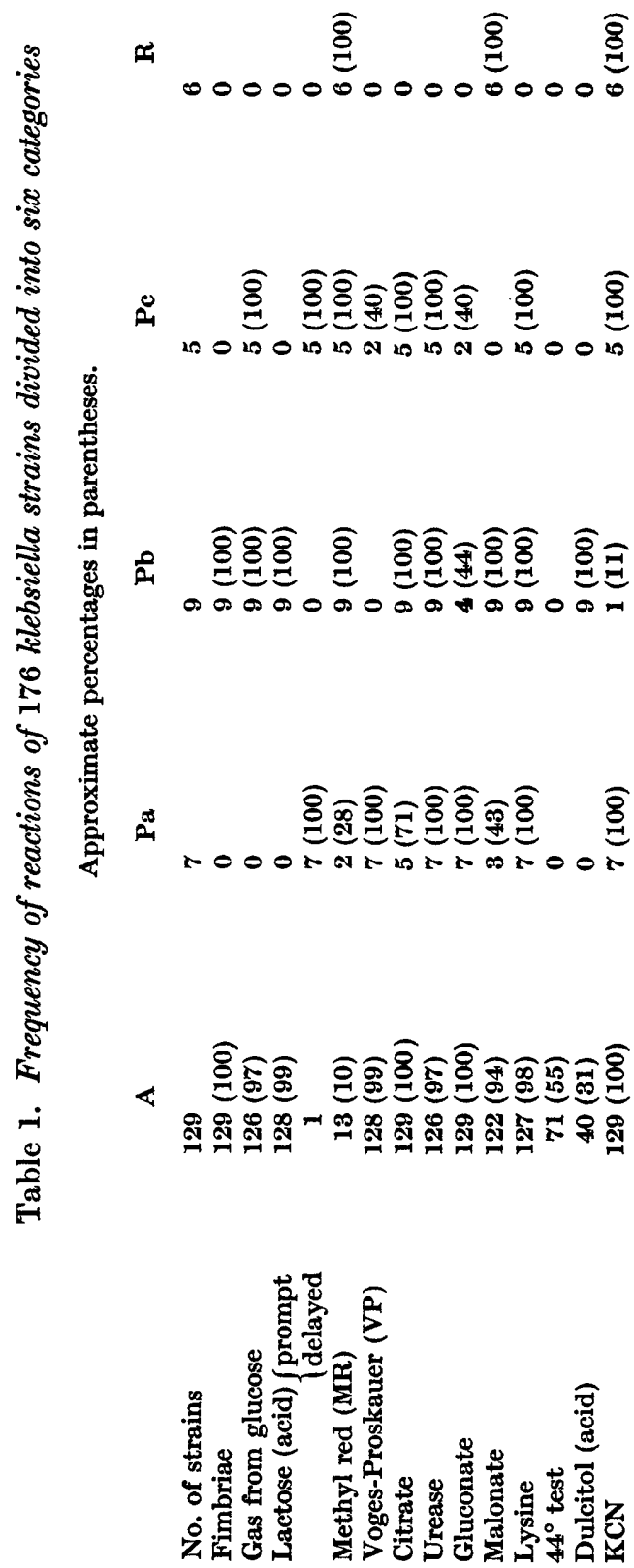
Strains which did not fit into these three categories were subdivided into a further three categories $(\mathrm{Pa}, \mathrm{Pb}$ and $\mathrm{Pc})$ on fimbriation, their ability to produce gas from glucose at $37^{\circ}$, on the speed of lactose fermentation, fermentation of dulcitol, methyl red test, acetoin production (VP), production of alkali in a malonate medium and growth in the presence of KCN. The use of a prototype Determinator (Cowan $\&$ Steel, 1960) was of help in sorting these strains into the different categories, and when this was done the $\mathbf{1 7 6}$ strains gave the reactions shown in Table 1.

Fimbriate strains often have adhesins and categories $\mathbf{A}$ and $\mathrm{Pb}$ could usually be distinguished from the other categories by tests for these characters. Of the 129 A strains, 120 had MR adhesin and 112 MS adhesin, whereas none of the $9 \mathrm{~Pb}$ strains had MR adhesin but all had MS adhesin. However, since the adhesins may vary independently and strains possessing both (as in A) may fail to show one of them in certain cultures (Duguid, 1959), they were excluded from further consideration as distinguishing tests.

A minority of the fimbriate strains were poorly fimbriate, their cultures showing not more than 5-25\% of bacilli with fimbriae; all 9 strains of category $\mathrm{Pb}$ were of this type. By analogy with other fimbriate bacteria (e.g. Shigella flexneri and Salmonella typhi-murium) we may expect that $\mathrm{A}$ or $\mathrm{Pb}$ might include a few non-fimbriate mutant strains, while $\mathrm{Pa}, \mathrm{Pc}, \mathrm{R}$ and $\mathrm{O}$ strains would in all cases be non-fimbriate (as Shigella sonnei). In fact, no strain with the biochemical reactions typical of $\mathrm{A}$ or $\mathrm{Pb}$ was found to be non-fimbriate, but we must accept the possibility of this.

To make a diagnostic table (Table 6) percentages shown in Table 1 were converted to symbols; below $25 \%$ was recorded as - (negative), above $75 \%$ as + (positive) and the intermediate percentages as $d$, to indicate that different strains gave different results. The word variable was avoided as $d$ characters of the individual strains were generally stable.

Table 2. Distribution of 176 strains among the six categories graded according to number of discrepancies

Discrepancies
None
$\mathbf{1}$
$\mathbf{2}$
$\mathbf{3}$

$\begin{array}{rccccr}\text { A } & \text { Pa } & \text { Pb } & \text { Pc } & \text { R } & 0 \\ 106 & 7 & 8 & 5 & 6 & 12 \\ 18 & 0 & 1 & 0 & 0 & 7 \\ 3 & 0 & 0 & 0 & 0 & 1 \\ 2 & 0 & 0 & 0 & 0 & 0\end{array}$

The percentage values of $d$ affect the worth of the diagnostic table. Since, by chance alone, many tests could be expected to give an equal number of + and - results, we can assume that a test of value (e.g. gas from glucose) will be either 100 or $0 \%$ (or near), and that a test of no distinguishing value will be around $50 \%$. If we make our $d$ broad (e.g. 25-75\%) our classification (and our distinguishing tests) will be firmly based, but we can expect many $d$ characters, and only a few well differentiated categories. If we make the $d$ range narrow, we should have fewer $d$ 's and better differentiation between the categories, but unless we are prepared to accept a great many categories, a high proportion of strains would show several discrepancies.

Strains which did not fit exactly into one of the six categories we defined were 


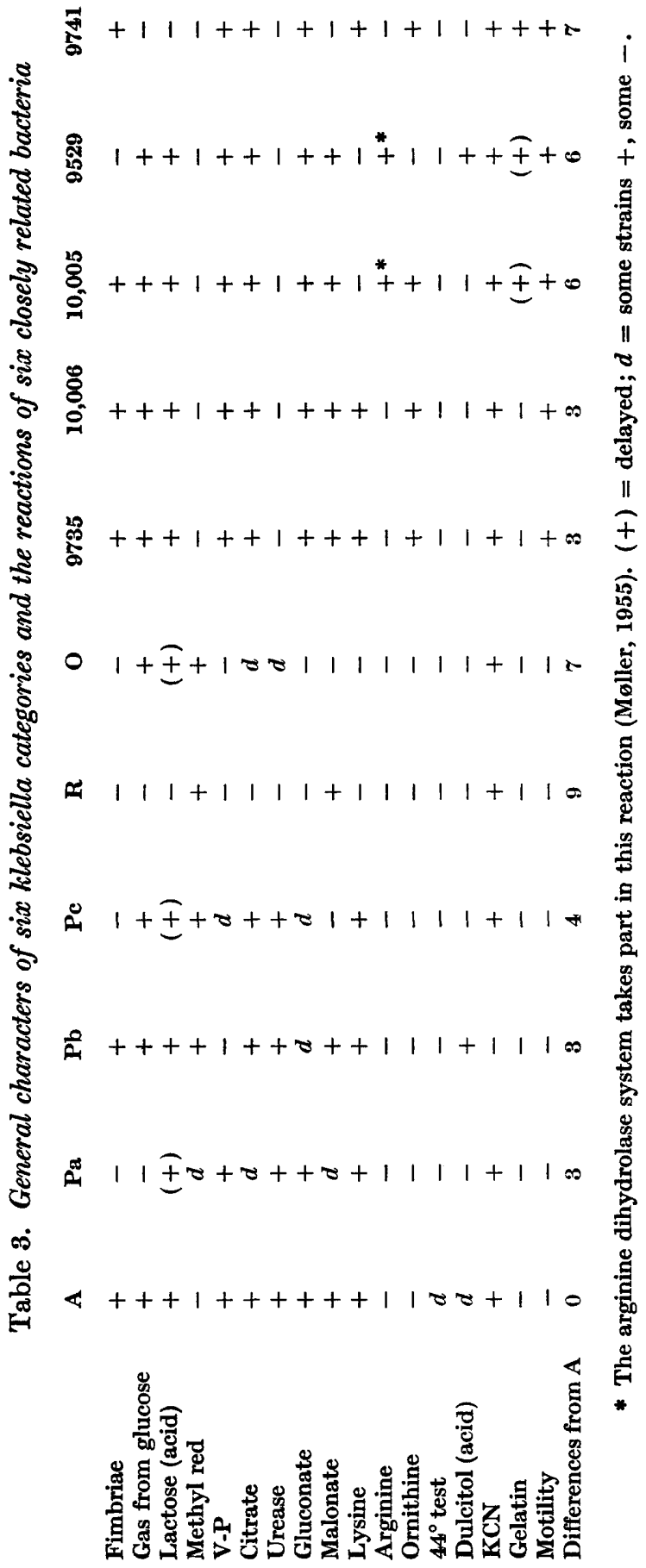


put into the nearest and the number of discrepancies recorded. When a character was described as $d$ it could not contribute to the discrepancies shown by a strain. From this sorting the results shown in Table 2 were obtained. Eight indole-producing strains had all other characters typical of category $\mathbf{A}$, and they were included in the 129 strains. From Table 2 it will be seen that the most of our 176 klebsiella strains fitted into the categories without showing more than one discrepancy; four had two, and two had three discrepancies.

Table 3 shows the reaction of the six closely related enterobacteria in the same distinguishing tests, and it also shows the reactions (arginine and ornithine decarboxylases, motility and gelatin liquefaction) which exclude them from the Klebsiella group. NCTC 10006, the type strain of Enterobacter aerogenes Hormaeche \& Edwards, has the same characters as NCTC 9735, but the latter is of additional interest in possessing the capsular antigen of Klebsiella serotype 47. Both these strains differ from our A category in only three characters, and show a closer relation than the other four strains to the Klebsiella group.

Table 4. Correlation of strain source with category

\begin{tabular}{cccc} 
& \multicolumn{3}{c}{ Source } \\
\cline { 2 - 4 } Category & Respiratory & $\begin{array}{c}\text { Non- } \\
\text { respiratory }\end{array}$ & Unknown \\
$\mathbf{A}$ & 59 & 61 & 9 \\
$\mathrm{~Pa}$ & 4 & 1 & 2 \\
$\mathbf{P b}$ & 4 & 1 & 4 \\
$\mathbf{P c}$ & 4 & 0 & 1 \\
$\mathbf{R}$ & 6 & 0 & 0 \\
O & 13 & 0 & 7 \\
Totals & 90 & 63 & 23
\end{tabular}

Table 5. Correlation between fimbriation, serotype and category

$\begin{array}{ccl}\text { Category } & \text { Fimbriae } & \text { Serotypes } \\ \mathbf{A} & + & \mathbf{1 , 2 , 4 - 6 9} \\ \mathbf{P a} & - & \mathbf{1 , 2} \\ \mathbf{P b} & + & \mathbf{3} \\ \mathbf{P c} & - & \mathbf{1} \\ \mathbf{R} & - & \mathbf{3} \\ \mathbf{O} & - & \mathbf{4 , 5}, \mathbf{6}\end{array}$

Correlation of the sources of the strains with the six categories was made when this was possible, but the sources of some strains remained unknown even after Dr P. R. Edwards had searched his records for us. One of our main interests in this investigation was to try to pick out Friedländer's bacillus from the nonrespiratory organisms that were culturally similar; we described sources, therefore, under these three simple headings: respiratory, non-respiratory and unknown. Table 4 shows the relations between source and our categories.

Duguid (1959) suggested a correlation between fimbriation and serotype and, since the serotype of most of the strains was known, it was possible to see that there was a correlation between our categories and these features (Table 5). 


\section{DISCUSSION}

Most workers have maintained that it was not possible to distinguish between the saprophytic Bacterium lactis aerogenes Escherich (syn. Aerobacter aerogenes Beijerinck) and Friedländer's pneumobacillus, but Duguid's (1959) suggestion that this might be possible made us review the characters of these organisms in the light of recent advances in bacterial characterization. Thus by studying the morphological features revealed by electron microscopy and combining this with the results of certain biochemical tests we have been able to divide our klebsiella strains into six categories. Differences between the categories depend on combinations of different characters, not all of which will vary in the same way in the same strain. Thus, $\mathrm{A}$ and $\mathrm{Pb}$ have only three completely different characters (KCN, methyl red and VP) but the $d$ character dulcitol in $\mathbf{A}$ is a + character in $\mathrm{Pb}$; similarly gluconate is + in $\mathrm{A}$ and $d$ in $\mathrm{Pb}$ and it is unlikely that a strain would show the less typical reaction in both characters.

$\mathrm{Pa}$ and $\mathrm{Pc}$ have only one absolute distinguishing character (the ability to produce gas from glucose at $37^{\circ}$ ) but $d$ occurs in five positions in the Table 6 distinguishing characters. In practice it is not difficult to distinguish between these categories, and the five strains in $\mathrm{Pc}$ do not fit $\mathrm{Pa}$ at all well. Pc has several features in common with $\mathbf{O}$ but, again, in practice there is no difficulty in distinguishing the categories.

A point we have not stressed, because the information is not usually available, is that the different categories are mainly made up of different serotypes; thus while $\mathrm{A}$ has representatives of all known serotypes except type 3 , our $\mathrm{Pb}$ strains are exclusively of serotype 3 with one non-capsulate (and therefore untypable) strain, our Pa strains all of types 1 or 2 , and our Pc strains all of type 1 . It is of course possible that had more strains of the higher serotypes been examined some might have been found to belong to biochemical categories other than $A$.

Strains of category $O$ show more individual differences than those of the other categories, and four strains of serotype 4 failed to reduce nitrate. Our results, taken in conjunction with those obtained by Dubay (1959), who examined 150 strains of Klebsiella ozaenae of serotype 4, suggest that this category might be divisible into two subcategories. Serotype 4 strains are usually urease-negative, whilst $\mathbf{O}$ strains of serotypes 5 and 6 are often positive in this character.

This classification of the Klebsiella group is applicable whatever taxonomic rank the group may be assigned. In schemes where the group is given generic rank our categories will be species; if the group is regarded as a species, our categories will be subspecies. In the discussion of nomenclature which follows, and in the selection and designation of nomenclatural types, the Klebsiella group is regarded as a genus.

In collecting strains we excluded from our Klebsiella group all motile strains; these are better regarded as belonging to Enterobacter (Hormaeche \& Edwards, 1960), Serratia or Hafnia. Neither did we include any gelatin-liquefying strains. We agree with Lautrop (1956) that the so-called Klebsiella oxytocum would be better removed from the Klebsiella group.

NCTC 204 is reputed to be one of Friedländer's strains; it is now non-capsulate and thus is not fully representative of the species Klebsiella pneumoniae. It belongs to category $\mathrm{Pb}$, which can therefore be considered to represent that species. Whilst 
NCTC 204 cannot be typed on the basis of its capsular antigen, Kauffmann (1949) found it to belong to $\mathrm{O}$ group 1 ; NCTC 5056 (also in our category $\mathrm{Pb}$ ) belonged to this $\mathbf{O}$ group but other strains of capsule type 3 (in our category $\mathbf{R}$ ) belonged to $\mathrm{O}$ group $2 \mathrm{~A}$. The designation of category $\mathrm{Pb}$ as $K$. pneumoniae is in line with the thinking of Henriksen (1952) who thought that dulcitol-fermentation was a character of the species. Since NCTC 204 is non-capsulate, we propose another strain CDC 298/53 (NCTC 9633, ATCC 13,883) as neotype of the species Klebsiella pneumoniae Trevisan.

With the type species characterized, we next turn to the identification of the other categories. A is made up of organisms that would be accepted the world over as Aerobacter aerogenes Beijerinck. An unexpected finding was that about $50 \%$ of the strains produced gas from MacConkey broth at $44^{\circ}$. These $44^{\circ}$-positive IMViC -++ strains are widely distributed, and have been named the 'yarn organism' (Mackenzie, Taylor \& Gilbert, 1948); they correspond to Irregular type VI of Report (1935). Perhaps they are worthy of subspecific status, but this we would not propose without further study.

The binomial Klebsiella aerogenes was proposed and must be ascribed to a Subcommittee of the Society for Applied Bacteriology (Report, 1956). A type culture was not designed by the Subcommittee, and we have chosen and propose as neotype strain C37 isolated at the Metropolitan Water Board Laboratories from water (NCTC 8172, ATCC 13,882); this strain is $44^{\circ}$-negative.

Category $\mathrm{O}$ is Klebsiella ozaenae (Abel) Bergey et al. As this category is biochemically less homogeneous than the others, we do not at present feel justified in selecting a neotype culture. Further study of a larger number of strains may show that division into two varieties is desirable.

Category $\mathbf{R}$ is Klebsiella rhinoscleromatis Trevisan. We propose strain $\mathbf{R} 70$ (NCTC 5046, ATCC 13,884) as the neotype culture.

We are left with the two categories $\mathrm{Pa}$ and $\mathrm{Pc}$; these have many characters in common and we regard them as two varieties of one species. It is not possible to assign to them a specific epithet from the past, and $\mathbf{P a}$ we name Klebsiella edrwardsii after P. R. Edwards of Atlanta, who has done so much to establish the serological classification of klebsiellas. Since we are also making a variety of the species, the name becomes $K$. edwardsii var. edwardsii and we designate strain F1 (NCTC 5054, ATCC 13,886) as type strain. Pc becomes the second variety which we name $K . e d w a r d s i i$ var. atlantae designating strain CDC 4610-53 (NCTC 9496, ATCC13,887) as type strain.

Descriptions of the neotype and holotype strains are given in the Appendix.

The classification makes use of fimbriation, a character that can be detected directly only by those with access to an electron microscope. Alternatively, an almost certain indication of the presence or absence of fimbriae may be gained by testing $37^{\circ}$ and $30^{\circ}$ broth cultures for haemagglutination of guinea-pig red cells (MS adhesin) and tanned ox red cells (MR adhesin). However, the determination of this character is not essential for the identification of the species and subspecies defined, though all relevant information is helpful, and the more characters that are known, the clearer the identification becomes. Only those characters necessary for the differentiation of the species are included in the table for use in the Determinator (Table 6). 
Any new scheme of classification should be compared with the old; our scheme supplements rather than replaces those based on serology (Julianelle, 1926; Kauffmann, 1949; Brooke, 1951; Edwards \& Fife, 1952; Edmunds, 1954; Ørskov, 1954, 1955). It provides a means of characterizing species within the genus and, we hope, will help to bring classification of the Enterobacteriaceae into line with other groups of bacteria in which genera are split into species which in turn are subdivided into serotypes or other subspecific taxa.

Table 6. Distinguishing characters of six categories

Table for use in Determinator (Cowan \& Steel, 1960).

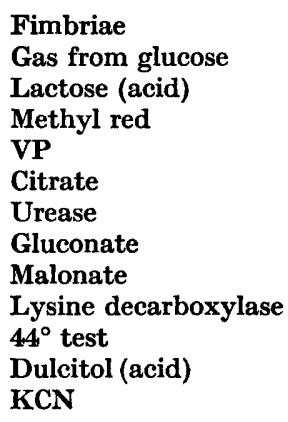

$\begin{array}{cc}\text { A } & \text { Pa } \\ + & - \\ + & - \\ + & (+) \\ - & d \\ + & + \\ + & d \\ + & + \\ + & + \\ + & d \\ + & + \\ d & - \\ d & - \\ + & +\end{array}$

$\mathrm{Pb}$
+
+
+
+
$\overline{+}$
+
$d$
+
+
+
+

Pc
-
+
$(+)$
+
$d$
+
+
$d$
-
+
-
-
+

$\begin{array}{cc}\mathbf{R} & \mathbf{O} \\ - & - \\ - & + \\ \overline{+} & (+) \\ - & + \\ - & \bar{d} \\ - & d \\ - & - \\ + & - \\ - & - \\ - & - \\ - & - \\ + & +\end{array}$

$\mathbf{A}=$ Klebsiella aerogenes (Beijerinck) Subcom. Soc. Appl. Bact.; Pa $=K$. edwardsii var. edroardsii n.sp.; $\mathbf{P b}=K$. pneumoniae Trevisan; $\mathrm{Pc}=K$. edwardsii var. atlantae subsp.n.; $\mathbf{R}=K$. rhinoscleromatis Trevisan; $\mathrm{O}=\mathrm{K}$. ozaenae (Abel) Bergey et al. $;(+)=$ delayed; $d=$ some strains + , some -.

Table 7. Characters of proposed neotype and designated holotype cultures

\begin{tabular}{|c|c|c|c|c|c|}
\hline & $\begin{array}{l}\text { Klebsiella } \\
\text { aerogenes }\end{array}$ & $\begin{array}{c}\text { K. pneu- } \\
\text { moniae }\end{array}$ & $\begin{array}{c}\text { K. rhino- } \\
\text { scleromatis }\end{array}$ & $\begin{array}{c}\text { K. edwaardsii } \\
\text { var. } \\
\text { edwaardsii }\end{array}$ & $\begin{array}{c}\text { K. edroardsii } \\
\text { var. } \\
\text { atlantae }\end{array}$ \\
\hline NCTC number & $8,172 \times$ & $9,633 \times$ & 5,046 & 5,054 & 9,496 \\
\hline ATCC number & 13,882 & 13,883 & 13,884 & 13,886 & 13,887 \\
\hline Serotype & 64 & $\mathbf{3}$ & $\mathbf{3}$ & 1 & 1 \\
\hline Gas from glucose at $37^{\circ}$ & + & + & - & - & + \\
\hline Acid from lactose & + & + & - & $(+)$ & $(+)$ \\
\hline Acid from starch & + & + & - & $(+)$ & + \\
\hline Acid from glycerol & + & + & $(+)$ & + & $(+)$ \\
\hline Acid from dulcitol & - & $+d$ & - & - & - \\
\hline Methyl red & - & + & + & + & + \\
\hline VP & + & - & - & + & + \\
\hline Gluconate & + & - & - & + & + \\
\hline Malonate & + & + & + & + & - \\
\hline Urease & + & + & - & + & + \\
\hline Lysine decarboxylase & + & + & - & + & + \\
\hline Growth in KCN medium & + & - & + & + & + \\
\hline Growth in Koser's citrate & + & + & - & + & + \\
\hline Simmons' citrate & + & + & - & + & + \\
\hline Christensen's citrate & + & + & + & + & + \\
\hline Fimbriae & + & + & - & - & - \\
\hline MR adhesin & + & - & - & - & - \\
\hline MS adhesin & + & + & - & - & - \\
\hline
\end{tabular}

Key to carbohydrate fermentation: $+=$ positive in $1-2$ days; $(+)=$ positive in $3-14$ days. 
We wish to thank all those who sent us strains and especially Dr P. R. Edwards who serotyped for us many of our untyped strains.

\section{APPENDIX}

\section{Descriptions of Proposed Neotype and Designated Holotype Cultures}

\section{Common characters}

Non-motile, non-pigmented, capsulate Gram-negative rods. Grow readily on ordinary media. Aerobic, facultatively anaerobic. Catalase-positive, oxidasenegative. Gelatin not liquefied. Indole not formed. Nitrate reduced to nitrite. Hydrogen sulphide produced from cysteine-containing medium. Phenylalanine deaminase and arginine and ornithine decarboxylases absent. Starch not hydrolysed. No gas from MacConkey broth at $44^{\circ}$. Acid from glucose fermentatively. Acid from arabinose, xylose, rhamnose, galactose, mannose, maltose, sucrose, trehalose, adonitol, mannitol, sorbitol, inositol and salicin.

Distinguishing characters are shown in Table 7.

\section{REFERENCES}

BArritT, M. M. (1936). The intensification of the Voges-Proskauer reaction by the addition of $\alpha$-naphthol. J. Path. Bact. 42, 441.

Brinton, C. C. (1959). Non-flagellar appendages of bacteria. Nature, Lond. 183, 782.

Brooke, M. S. (1951). Further capsular antigens of Klebsiella strains. Acta path. microbiol. scand. 28, 313.

Catalogue of the National Collection of Type Cultures (1922). 1st ed. Spec. Rep. Ser. med. Res. Coun., Lond. no. 64.

Clatke, P. H. (1953). Hydrogen sulphide production by bacteria. J. gen. Microbiol. 8, 397.

Cowan, S. T. \& Steel, K. J. (1960). A device for the identification of microorganisms. Lancet, i, 1172.

Dubay, L. (1959). K otázke biochemických vlastností Klebsiely typu 4 (Ozaenae). Čsl. epidemiol. mikrobiol. imunol. 8, 235.

Duguid, J. P. (1951). The demonstration of bacterial capsules and slime. J. Path. Bact. 63, 673.

Duguid, J. P. (1959). Fimbriae and adhesive properties in Klebsiella strains. J. gen. Microbiol. 21, 271.

Duguid, J. P., Smith, I. W., Dempster, G. \& Edmunds, P. N. (1955). Non-flagellar filamentous appendages ('Fimbriae') and haemagglutinating activity in Bacterium coli. J. Path. Bact. 70, 335.

Edmunds, P. N. (1954). Further klebsiella capsule types. J. infect. Dis. 94, 65.

EDwards, P. R. (1929). Relationships of the encapsulated bacilli with special reference to Bact. aerogenes. J. Bact. 17, 339.

Edwards, P. R. \& Fife, M. A. (1952). Capsule types of klebsiella. J. infect. Dis. 91, 92.

Falkow, S. (1958). Activity of lysine decarboxylase as an aid in the identification of Salmonellae and Shigellae. Amer. J. clin. Path. 29, 598.

Frankland, P. F., Stanley, A. \& Frew, W. (1891). Fermentations induced by the Pneumococcus of Friedländer. J. Chem. Soc. 59, 253.

Gostrngs, W. R. O. \& SNIJDERS, E. P. (1936). Untersuchungen über das Scleroma respiratorium (Sklerom). IV. Mitteilung. Die antigene Struktur der Skleromstämme im Vergleich mit den anderen Kapselbakterien. Zbl. Bakt. (1. Abt. Orig.), 136, 1.

Grimbert, L. (1895). Recherches sur le pneumobacille de Friedländer. Ann. Inst. Pasteur, 9, 840.

Grimbert, L. \& Legros, G. (1900). De l'identité du bacille lactique aérogène. Ann. Inst. Pasteur, 14, 479. 


\section{2}

S. T. Cowan, K. J. Steed, C. Shaw and J. P. Duguid

Henriksen, S. D. (1952). Classification of the Klebsiella group. Acta path. microbiol. scand. 30, 230.

Holman, W. L. \& Gonzaxes, F. L. (1923). A test for indol based on the oxalic reaction of Gnezda. J. Bact. 8, 577.

Hormaeche, E. \& Edwards, P. R. (1960). A proposed genus Enterobacter. Int. Bull. bact. Nom. Tax. 10, 71 .

Hugh, R. \& LEIfSON, E. (1953). The taxonomic significance of fermentative versus oxidative metabolism of carbohydrates by various Gram-negative bacteria. J. Bact. 66, 24.

Julianelue, L. A. (1926). A biological classification of Encapsulatus pneumoniae (Friedländer's bacillus). J. exp. Med. 44, 113.

Kauffmann, F. (1949). On the serology of the Klebsiella group. Acta path. microbiol. scand. 26, 381.

Koser, S. A. (1923). Utilization of the salts of organic acids by the colon-aerogenes group. J. Bact. 8, 493.

LAUTrop, H. (1956). Gelatin-liquefying Klebsiella strains (Bacterium oxytocum (Flügge)). Acta path. microbiol. scand. 39, 375.

Mackenzie, E. F. W., Taylor, E. W. \& Grubert, W. E. (1948). Recent experiences in the rapid identification of Bacterium coli type I. J. gen. Microbiol. 2, 197.

Møluer V. (1954). Diagnostic use of the Braun KCN test within the Enterobacteriaceae. Acta path. microbiol. scand. 34, 115.

Mølner, V. (1955). Simplified tests for some amino acid decarboxylases and for the arginine dihydrolase system. Acta path. microbiol. scand. 36, 158.

Ørskov, I. (1954). O antigens in the Klebsiella group. Acta path. microbiol. scand. 34, 145.

Ørskov, I. (1955). Serological investigations in the Klebsiella group. I. New capsule types. Acta path. microbiol. scand. 36, 449.

Report (1935). Wilson, G. S., Twigg, R. S., Wright, R. C., Hendry, C. B., Cowell, M. P. \& Maier, I. The bacteriological grading of milk. Spec. Rep. Ser. med. Res. Coun., Lond. no. 206.

Report (1956). The Society for Applied Bacteriology. The nomenclature of coli-aerogenes bacteria. Report of the Coli-aerogenes (1956) Subcommittee. J. appl. Bact. 19, 108.

REPORT of the Enterobacteriaceae Subcommittee of the Nomenclature Committee of the International Association of Microbiological Societies (1958). Int. Bull. bact. Nom. Tax. 8, 25.

Shaw, C. \& Clarke, P. H. (1955). Biochemical classification of Proteus and Providence cultures. J. gen. Microbiol. 13, 155. 